\title{
The Utilization of ResearchGate for State Polytechnic Malang Lecturers
}

\author{
Hiqma Nur Agustina*, Nugrahaningtyas Fatma Anyassari, Maya Rizky Fauzia \\ English Department \\ State Polytechnic of Malang \\ Malang, Indonesia \\ *hiqma@polinema.ac.id,nfanyassari@polinema.ac.id, maya_fauzia8@polinema.ac.id
}

\begin{abstract}
Since research is one of the Three Pillars of Higher Education, lecturers should publish their research findings to public. A free site that facilitates academic publication is ResearchGate (RG). Objective of this study was to describe utilization of ResearchGate among lecturers of State Polytechnic of Malang. This study was a descriptive quantitative study where survey was employed as research method. The research instrument was questionnaire. Out of 580 questionnaires distributed, 72 were returned. The finding showed that $69 \%$ of the lecturers had RG account while the remaining $31 \%$ did not. The lecturers used RG to access current information on their respective field, increase publication, citation and readership as well as communicate and have discussion with other researchers. The result suggests that RG can be used to improve academic culture and quality in State Polytechnic of Malang.
\end{abstract}

Keywords-academic culture, ResearchGate, research, utilization

\section{INTRODUCTION}

Publication of scientific papers is a must for every lecturer. This concerns one of the tasks of the Three Pillars of Higher Education, namely conducting research and then publishing it in the form of scientific articles. In addition to increasing added value for the lecturers themselves, it also has an impact on the progress of institutional research. Several alternatives as a forum for publishing lecturer research results are quite diverse, such as national journals, international journals, and reputable international journals. Ministry of Education and Culture has divided it into several journal categories contained in the SINTA (Science and Technology Index), which is a portal containing the measurement of the performance of Science and Technology which includes the performance of researchers, writers, authors, journal performance and the performance of science and technology institutions consisting of six (6) categories ranging from SINTA 1 to SINTA 6.

In addition to journals, a lecturer can also present and publish scientific articles at national seminars and international conferences and the output is in the form of proceedings. As another alternative, lecturers can also publish it on an online research site that accommodates a lot of research by international academics, ResearchGate. This site is a tool that can be used to upload articles from lecturers' research results. The interesting side that is beneficial for lecturers is that many other researchers can access it for free and then cycle it. Another benefit is that it can open a space for discussion and cooperation if a researcher reads the work of a lecturer and then finds common ground and continues to collaborate in the research field.

Every researcher who is doing a research certainly really needs a reference, one of which is a scientific journal. This momentum must be understood by lecturers at the State Polytechnic of Malang to actively publish it. Among the research sites, ResearchGate is a free social networking website and collaboration tool for scientists of all kinds. This site provides a variety of web applications including abstract search, various files, publication databases, forums, methodology discussions, groups and various other applications. So wide is the opportunity for lecturers to share knowledge and disseminate publications, so the lecturers at Malang State Polytechnic should also be able to seize this golden opportunity.

Compared to other sites and collaboration tools, ResearchGate has developed a semantic Internet search tool capable of searching for research papers from internal sources and well-known external databases such as PubMed, CiteSeer, arXiv, NASA Library and so on. This internet search tool was developed to analyze words and expressions that are broader than those commonly used in other internet search tools by analyzing all abstracts of research papers so that they can get more accurate results.

This research is aimed at developing various kinds of applied research that has been carried out by the State Polytechnic of Malang academic community through uploading on the ResearchGate website. We hope by conducting an in-depth study of the understanding and importance of using the ResearchGate (RG) site, it can contribute to the development of scientific collaboration with international researchers and academics. The more collaborations that are carried out with researchers at the international level, the more it will improve the quality in the research and academic fields considering that in the current era the government is also actively encouraging all Indonesian 
citizens to participate actively in developing research and scientific potential.

\section{METHODS}

This study has been conducted using a survey method. The process of research that has been conducted followed several steps, namely: (1) collecting data, (2) storing data, (3) analyzing data, and (4) visualizing data. The process of collecting data is conducted during June 8 - August 31, 2020. The preliminary study that we have done is that the lecturers in State Polytechnic of Malang are not maximally registered, have a ResearchGate website account and actively upload their scientific articles. As a result, the State Polytechnic of Malang ResearchGate score is not optimal considering the total number of 530 lecturers recorded on the RG website is only 394.This data explains that not all lecturers at State Polytechnic of Malang know and use the ResearchGate website to increase their professionalism in the field. This research was conducted by distributing online questionnaires using google form since there is a COVID-19 pandemic. This paper seeks to investigate these two main issues: (1) What is the perception of State Polytechnic of Malang lecturers about the ResearchGate website? And (2) How do the ResearchGate website known and used as a medium for publishing scientific papers for lecturers at State Polytechnic of Malang? This paper will answer those questions to add the utilization of ResearchGate to the State Polytechnic of Malang lecturers.

\section{FINDINGS AND DISCUSSION}

The previous studies have conducted by some researchers. The benefits of social media in service development have been investigated [1]. Furthermore, it was stated that there were 1410 colleges or universities using Researchgate.net as a medium of communication, collaboration, and sharing articles through 596.634 users from 4445 colleges / universities in Indonesia on September 1, 2016. From the publications with a total of 4401 respondents, it showed that the tendency of academics and researcher publications in Indonesia is still low [2]. Results of research on the benefits of the ResearchGate website for academics in the Faculty Members of the University of Tehran's Engineering College in increasing awareness of research activities and the number of their citations were revealed [3]. A study conducted by Rahmani and Asnafi [4] discussed the negative influence of social networking Facebook among Asia Pacific academics in Malaysia and did not discuss the ResearchGate site. The research only focused on the consequences for academics who use the Facebook social network such as addiction, health problems from using this site for too long, and also related to the privacy of those who are often victims of hackers. On the other hand, research that is consistently published in journals, academic websites will provide positive values for researchers Abdulahi and Samadi [5]. Another study Ebrahim [6] suggests that research that is easily found by other researchers will be able to increase the number of citations to their scientific publications [6]. A study by Jones and Evans [7] examined
2172 articles and found that there was a positive relationship between the number of downloads and citations. Other studies have also shown that there is a correlation between articles that are frequently cited and easily searched online as well as having a positive impact on these researchers Jamali and Nikzad [8]. The use of blogs and podcasts for discussion by researchers on the internet can also increase positive value [9]. The importance of joining academic social networking sites is also an important point and becomes the basis for this research Taylor \& Francis Group [10]. It is also believed that a number of Web 2.0 tools such as Wiki and Blogs can be used to inform, explain and create links for other people's research for publication purposes [11].

Total respondents were 72 lecturers of State Polytechnic of Malang which consisted of $38(53 \%)$ male respondents and 34 (47\%) female respondents. The respondents came from the seven departments in the institution, namely Business Administration (16 respondents or 22\%), Accounting (3 respondents or 4\%), Mechanical Engineering (8 respondents or $11 \%$ ), Civil Engineering (9 respondents or 13\%), Electrical Engineering (13 respondents or 18\%), Chemical Engineering (8 respondents or 11\%) and Informatic Engineering (15 respondents or $21 \%$ ). In terms of years of service, 45 respondents $(63 \%)$ have been working for 0-5 years, 5 respondents $(7 \%)$ have been working between 5 and 10 years, 10 respondents have been working for $10-15$ years and 12 respondents $(17 \%)$ have been working for the institution for more than 20 years. Out of 72 respondents, 50 (69\%) had ResearchGate accounts while the remaining $22(31 \%)$ did not. Figure 1 shows numbers of lectures who have ResearchGate accounts.

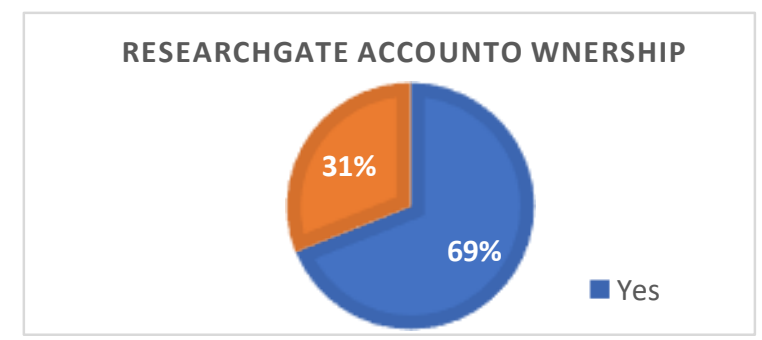

Fig. 1. State Polytechnic of Malang Lecturers and ResearchGate account

Based on the data from 50 respondents who had ResearchGate accounts, 8 respondents (16\%) had ResearchGate account for less than one year, 10 respondents (20\%) had the account for 1-2 years, 25 respondents $(50 \%)$ had ResearchGate accounts for 2-5 years, and 7 respondents $(14 \%)$ had the account for more than five years. In terms of frequency, 7 respondents (14\%) accessed their ResearchGate accounts once a week, 7 respondents (14\%) accessed their accounts twice a week, 15 respondents $(30 \%)$ accessed it once a month, and 14 respondents (28\%) accessed their ResearchGate accounts only when they needed references for their research.

The respondents used ResearchGate for various purposes. Most respondents took advantage of ResearchGate to download other people's articles (16 respondents or 32\%). The 
second and third most frequent activities were to upload own articles and download other people's articles (6 respondents or $12 \%)$ and upload own articles and check number of citations (3 respondents or 6\%). The respondents also accessed ResearchGate for downloading other people's articles and checking number of citations for own writings (3 respondents or $6 \%$ ), checking number of citations for own writings (2 respondents or $4 \%$ ), reading, looking for, and looking at references ( 2 respondents or $4 \%$ ), downloading other people's articles and reading, looking for, or looking at references (2 respondents or 4\%), uploading own writing (1 respondent or $2 \%$ ) and all of the above activities (13 respondents or 26\%). Figure 2 summarizes how State Polytechnic of Malang lecturers utilized ResearchGate.

\section{Utilization of ResearchGate among Lecturers}

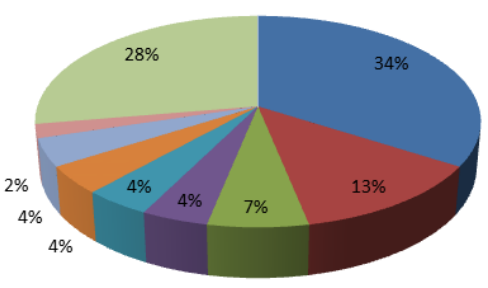

Upload own's article and download other's articles

Upload own's article and check number of citations

- Download other's articles and check number of citation for own writings

Check number of citations of own writings

Fig. 2. Utilization of ResearchGate Sites in State Polytechnic of Malang.

ResearchGate had positive advantages toward the respondents. 13 respondents $(26 \%)$ stated that ResearchGate increased their motivation to write, 7 respondents (14\%) were more active in writing and more active in publishing their research results, 7 respondents (14\%) were more active in publishing their research after setting up ResearchGate account, and 7 respondents used ResearchGate to find references (previous research findings) for their research. Furthermore, 3 respondents $(6 \%)$ were more active in publishing their research, 2 respondents $(4 \%)$ were encouraged to collaborate with other researchers from other institutions and 1 respondent $(2 \%)$ was more active in writing and making collaboration with other universities. Smaller percentage of the respondents used the site to expand the network (2\%), update number of own citation $(2 \%)$ and 6 respondents (12\%) used ResearchGate for all purposes mentioned above.

As an addition, motivations for using ResearchGate also varied widely. $88 \%$ of the respondents agreed that the site can be used for the dissemination of academic research result or to publish scientific articles. Regarding ResearchGate as source of information, $90 \%$ agreed that ResearchGate enabled them to download scientific articles in their discipline, while $56 \%$ used the site to download articles outside their discipline. Besides that, $82 \%$ of the respondents agreed that ResearchGate helped them keep up with the most current topics in their discipline. Regarding citations and readership, $68 \%$ of the respondents used the site to find out number of citations of their articles,
$68 \%$ wanted to identify how many times their articles had been read by other people, and $68 \%$ wanted to increase readership of their publications. Furthermore, in terms of networking, $80 \%$ of respondents agreed that their motivation for using the ResearchGate website was to discuss with other researchers from the same discipline, while $58 \%$ wanted to discuss with researchers from other discipline. The data show in table 1 bellow:

TABLE I. MOTIVATION FOR UTILIZING RESEARCHGATE FOR SCIENTIFIC PUblication IN STATE POLYTECHNIC OF MALANG

\begin{tabular}{|l|l|l|}
\hline 1 & Download scientific article in own discipline & $90 \%$ \\
\hline 2 & Discuss with other researchers from similar discipline & $90 \%$ \\
\hline 3 & Publish scientific article & $88 \%$ \\
\hline 4 & Keep up with current trends in own discipline & $82 \%$ \\
\hline 5 & Find out number of citations & $68 \%$ \\
\hline 6 & Increase readership & $68 \%$ \\
\hline 7 & Discuss with researchers from different discipline & $58 \%$ \\
\hline 8 & Download article from in other disciplines & $56 \%$ \\
\hline
\end{tabular}

In other words, $44 \%$ of the respondents were motivated to use ResearchGate to get references to increase their knowledge, while $34 \%$ of them used it to increase readership and their citation of writing. In addition, $6 \%$ of the respondents took advantage of the site to develop networking, $4 \%$ of them used ResearchGate as it is user-friendly and $2 \%$ used it as the requirement to create SINTA, Science and Technology Index, an online scientific portal run by Indonesian Ministry of Higher Education and Research

The respondents acknowledged benefit of ResearchGate toward themselves and their publication. Majority of the respondents $(66 \%)$ stated ResearchGate allowed them to access free references in their discipline and update current trends and issues in their discipline. $16 \%$ of them experienced improvement in communication and networking, whereas $14 \%$ experienced increase in citation. In conclusion, more than $50 \%$ of the respondents agreed that ResearchGate enhanced access to various references and helped increase number of citations if managed properly.

Based on the questionnaire, 22 respondents did not have ResearchGate account. Half of them $(50 \%)$ mentioned other academic social networking sites, while $23 \%$ claimed that ResearchGate did not have significant influence toward their publication. Co-worker also influenced utilization of ResearchGate in State Polytechnic of Malang as 9\% of the respondents decided not to set up ResearchGate account because none of their co-workers used ResearchGate. 5\% of the respondents did not set up ResearchGate account since they could not find references they needed in the site, $9 \%$ of them were not familiar with ResearchGate and $5 \%$ had yet to have any scientific publication. Presentation the reason Utilizing ResearchGate show in table 2. 
TABLE II. REASONS FOR NOT UTILIZING RESEARCHGATE

\begin{tabular}{|l|l|l|}
\hline 1 & Other academic social networking sites & $50 \%$ \\
\hline 2 & $\begin{array}{l}\text { ResearchGate had no significant impact toward } \\
\text { scientific publication }\end{array}$ & $23 \%$ \\
\hline 3 & Co-workers did not use ResearchGate & $9 \%$ \\
\hline 4 & Unfamiliar with ResearchGate & $9 \%$ \\
\hline 5 & $\begin{array}{l}\text { ResearchGate did not provide references the } \\
\text { respondents needed }\end{array}$ & $5 \%$ \\
\hline 6 & No scientific publication & $5 \%$ \\
\hline
\end{tabular}

The biggest obstacle the respondents had was to understand method for developing network on ResearchGate (36\%). Other obstacles were lack of understanding on how to set up ResearchGate account (23\%), lack of information about ResearchGate (14\%) and lack of information on how to upload article on ResearchGate (9\%). However, $91 \%$ of the respondents who did not have ResearchGate account planned to set up one. The data show in figure 3 .

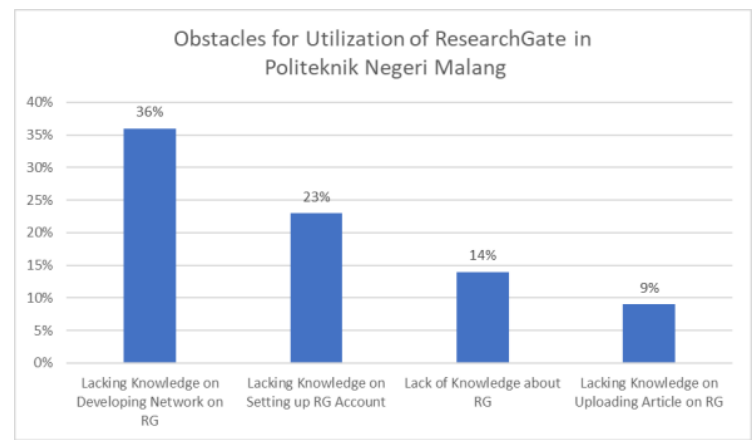

Fig. 3. Obstacles for Utilization of ResearchGate in Politeknik Negeri Malang.

State Polytechnic of Malang has conducted various programs and provided facilities to boost scientific publication of their faculty, for instance internet (24\%), incentives (14\%), training $(14 \%)$ and official circulation letter on scientific publication $(7 \%)$. However, only $40 \%$ of respondents are familiar with the programs or facilities.

The respondents expected that State Polytechnic of Malang launched program that aims to increase number of scientific publications. Most of the respondents (29\%) opted for academic writing workshop, while $15 \%$ hoped that State Polytechnic of Malang provided incentive related to scientific publication. Other facilities the respondents expected were the internet (8\%), access to international journal (8\%), and networking and communication with researchers from foreign countries $(5 \%)$ (See Table 3$)$.
TABLE III. PROGRAMS AND FACILITIES TO IMPROVE SCIENTIFIC PUBLICATION

\begin{tabular}{|l|l|l|}
\hline 1 & Scientific writing workshop & $29 \%$ \\
\hline 2 & Incentives & $15 \%$ \\
\hline 3 & Internet & $8 \%$ \\
\hline 4 & Access to International Journal & $8 \%$ \\
\hline 5 & $\begin{array}{l}\text { Networking and Communication with Researchers from } \\
\text { Foreign Countries }\end{array}$ & $5 \%$ \\
\hline
\end{tabular}

Disseminating research can be deemed as part of academia life. In this case, having social network might help a lot, ResearchGate for instance. As the findings of this survey shows that most of the respondents utilize ResearchGate to download others' articles within the same field. This is in line with [3] who conducted a survey for Iranian engineering lecturer. This tendency appears because conducting research needs a thread. Scholars should make sure about the niche of studies they are going to conduct by reviewing previous studies in the same field. By doing this, scholars assures that they are connecting the dots to build knowledge in their field.

The findings also showed that ResearchGate helps the respondents showcase their studies. By publishing their article on ResearchGate, academics can see the readership and the number of citations their articles have achieved. This is in line with Abdulahi and Samadi [5] who states that one of the ways to promote articles is through ResearchGate. Promoting the result of studies is important for scholars since it contributes to self-recognition for their career growth. On the contrary, the findings of Wong [12] study suggest that in the American and European countries, academics are not very active users of the site. Overall, the results of their research have practical implications, especially for American and European scholars.

\section{CONCLUSION}

As one of the free social networking websites and collaboration tools for scientists, ResearchGate can be used to publish research results, search for reference sources, and also be a means to collaborate with other researchers in the world. The maximum use of the ResearchGate site will be able to provide positive values not only for a scholar, but also for the university. This research in particular provides benefits in building the awareness of lecturers at State Polytechnic of Malang to actively utilize the ResearchGate site in research activities.

\section{ACKNOWLEDGMENT}

The researchers thank State Polytechnic of Malang, Indonesia for the provided support and funding. 


\section{REFERENCES}

[1] C.K. Widada, "Mengambil Manfaat Media Sosial Dalam Pengembangan Layanan," Journal of Documentation and Information Source, 2018.

[2] S.N. Edi, K. Djati, W. I Made, and M.K. Tubagus, "Researchgate data analysis to measure the strength of Indonesian research" Far East Journal of Electronics and Communications, vol. 17, no. 5, pp. 1177-1183, 2017.

[3] M. Rahmani and A.R. Asnafi, "Utilizing ResearchGate Social Network by Iranian engineering. Library Philosophy and Practice (e-journal), 2017.

[4] A. Abdulahi and B. Samadi, "A Study on the Negative Effects of Social Networking Sites Such as Facebook among Asia Pacific University Scholars in Malaysia," International Journal of Business and Social Sciences, Vol. 5, No.10, September 2014.

[5] N.A. Ebrahim, "Effective Strategies for Increasing Citation Frequency," International Education Studies, Vol. 6, No. 11, 2013. Canadian Center of Science and Education.

[6] K. Jones and K. Evans, Good Practices for Improving Citations to your Published Work, pp. 2. 2013. University of BATH
[7] H.R. Jamali and M. Nikzad, "Article title type and its relation with the number of downloads and citations. Scientometrics," 88(2), 653-661, 2011.

[8] L. Vaughan and D. Shaw, "Bibliographic and Web citations: What is the difference?" Journal of the American Society for Information Science and Technology, vol. 54, no. 14, pp. 1313-1322, 2003.

[9] Taylor \& Francis Group. 2012a. Optimize citations. Retrieved May 9, 2013,from http://journalauthors.tandf.co.uk/beyondpublication/optimizingcitations. asp

[10] Taylor \& Francis Group, 2012b, Promote your article. Retrieved May 9 2013 from http://journalauthors.tandf.co.uk/beyondpublication/promotearticle.asp

[11] R. Wong, Ways to Maximise Citations for Researchers, pp. 1-7, 2008, University

Sheffield.http://journalauthors.tandf.co.uk/beyondpublication/optimizing citations.asp

[12] N. Muscandi and S. Utz. Social Networking for Scientist : An analysis on how and why academics use ResearchGate, Online Information Review, vol. 41, no. 5, pp. 744-759, 2017, Emeral Publishing Limited. 